\title{
Uniparental Disomy and Genomic Imprinting in Humans
}

Schinzel, A

\begin{abstract}
Uniparental disomy (UPD), the inheritance of both homologues from one chromosome from the same parent, was first proposed in 1980 by Erik Engel [1] to be a potential cause of congenital developmental defects in hymans. First hints from the premolecular era towards its existence came from instances where a pericentric inversion was present on one homologue in a parent and on both in one offspring [2] and where there was transmission of an interhomologous Robertsonian translocation (of chromosome 22) from a healthy mother to healthy offspring [3-4]. In mice, UPD was experimentally produced by crossing two mice lines with different Robertsonian translocations both involving the same chromosome [for 2 review see ref. 5].Through this approach, it was possible to define imprinted regions, chromosomes and chromosomal segments for which either maternal or paternal or both types of uniparental disomy led to phenotypic abnormalities. The latter are explained by genomic imprinting, the differential silencing of a gene or genes from one of the parents (the mother or the father) during any stage of embryogenesis or later in life. If, for example, the maternal homologue of a given gene is imprinted (and hence only the paternal allele is active), maternal UPD would lead to loss of the active allele and thus might cause consequences due to loss of function.
\end{abstract}

DOI: https://doi.org/10.1017/s0001566000001239

Posted at the Zurich Open Repository and Archive, University of Zurich

ZORA URL: https://doi.org/10.5167/uzh-155315

Journal Article

Published Version

Originally published at:

Schinzel, A (1996). Uniparental Disomy and Genomic Imprinting in Humans. Acta geneticae medicae et gemellologiae, twin research, 45(1-2):145-152.

DOI: https://doi.org/10.1017/s0001566000001239 


\title{
Uniparental Disomy and Genomic Imprinting in Humans
}

\author{
A. Schinzel \\ Institute of Medical Genetics, University of Zürich, Zürich, Switzerland
}

\section{INTRODUCTION}

Uniparental disomy (UPD), the inheritance of both homologues from one chromosome from the same parent, was first proposed in 1980 by Erik Engel [1] to be a potential cause of congenital developmental defects in hymans. First hints from the premolecular era towards its existence came from instances where a pericentric inversion was present on one homologue in a parent and on both in one offspring [2] and where there was transmission of an interhomologous Robertsonian translocation (of chromosome 22) from a healthy mother to healthy offspring [3-4]. In mice, UPD was experimentally produced by crossing two mice lines with different Robertsonian translocations both involving the same chromosome [for 2 review see ref. 5].

Through this approach, it was possible to define imprinted regions, chromosomes and chromosomal segments for which either maternal or paternal or both types of uniparental disomy led to phenotypic abnormalities. The latter are explained by genomic imprinting, the differential silencing of a gene or genes from one of the parents (the mother or the father) during any stage of embryogenesis or later in life. If, for example, the maternal homologue of a given gene is imprinted (and hence only the paternal allele is active), maternal UPD would lead to loss of the active allele and thus might cause consequences due to loss of function.

\section{Key words: Imprinting, Genomic, Uniparental disomy}

\section{Why study UPD in humans?}

The study of UPD in humans is an appropriate way to assess imprinted genes. Beyond that, however, UPD is a potential source for mapping recessive genes to a chromosome (in cases of isodisomy of the segment or the entire chromosome) and the knowledge of imprinted genes is also important for proper genetic counselling of couples after prenatal detection of UPD following determination of trisomy or mosaic trisomy at chorionic villus examinations. 


\section{Candidates for a UPD search}

Demonstration of UPD requires molecular genetic investigations. It is therefore important to know in which clinical and cytogenetic situations these investigations are indicated. Valuable candidates for UPD search are described below:

1. Translocations between homologous chromosomes. So far, about half of Robertsonian interhomologous translocations examined were instances of UPD [6]. Among the much less frequent interhomologous translocations between nonacrocentric chromosomes, UPD may be more frequent, being found in one instance for each of two isochromosomes (one for the short, the other for the long arm) replacing two homologues 4 [7] and 7 [8]. In addition, a patient with a translocation chromosome between the two number $8 \mathrm{~s}$ fused at their distal short arms, appeared to have maternal heterodisomy [Zuffardi, pers. commun; and own unpubl. obs.].

2. Propositus with abnormal phenotype showing the same seemingly balanced rearrangement as other healthy family members. The first instance of a well-recognized syndrome demonstrated to be due to loss of the active allele of an imprinted gene was a case with Prader-Willi syndrome (PWS) and balanced 13/15 Robertsonian translocation, whose mother and other healthy relatives had the same seemingly balanced rearrangement. Through molecular marker analysis, the authors could show-that the child had inherited both the translocation 15 and the normal 15 from the mother and no chromosome 15 from the father [9]. Prior to showing UPD, it was usually assumed that similar propositi had minor deletions due to unbalanced crossovers [10-11]. Further such instances have been reported for the PWS [12,13] the Angelman syndrome (AS) [11, 14] and maternal UPD 14 [15].

3. UPD may lead to homozygosity for mutated recessive alleles or for very rare alleles. In two cases with cystic fibrosis, maternal uniparental isodisomy was found by molecular marker analysis. Maternal uniparental isodisomy also led to homozygosity for a gene for rod monochromacy [16], and maternal UPD 15 was connected with, in addition to the Prader-Willi syndrome, Bloom syndrome [17]. Furthermore, at least two instances of severe cartilage hair hypoplasia with UPD 9 have been reported [18]. Homozygosity for the extremely rare allele of the fourth component of complement led to the detection of paternal isodisomy 6 [19].

4. Confined placental mosaicism. Any cytogenetic laboratory performing prenatal chromosome examinations from chorionic villi will come across instances of trisomy or mosaic trisomy of chromosomes, for which neither, or at least not the full trisomy, are compatible with intrauterine survival. In these instances, an amniocentesis or fetal blood examination is often performed that will normally show a diploid fetal karyotype. The trisomy is thus confined to the placenta. In most cases the indication for the examination is advanced maternal age, and it can be shown that the zygote was trisomic and the fetus survived because one of the three homologues was subsequently lost. Thus, trisomy or mosaic trisomy is confined to the placenta. In these instances, the risk of losing the single paternal 
homologue resulting in maternal UPD in the fetus is probably $1 / 3$. This has already been shown for UPD $14[20,21]$ UPD 15, connected with PWS [22, 23; own unpubl. obs.] and UPD 16 [24].

5. A potential further candidate for a UPD search would be a child with a multiple congenital anomalies/mental retardation (MCA/MR) syndrome or growth retardation born to an "old" mother, the mechanism being the same as outlined above under 4.

Simultaneous occurrence of two recessively inherited phenotypes in one individual could, at least if it cannot be excluded that both genes map to one and the same chromosome, be explained by UPD.

\section{Phenotypes due to UPD}

Table 1 lists all so far reported instances of UPD or segmental UPD in humans. In some of them, it is not known whether UPD by itself (through loss of the active allele of an imprinted gene) led to the phenotypic abnormalities. For example, the case with maternal UPD 8 has lost a telomeric segment of $8 p$ on both homologues involved in the $8 / 8$ translocation, and the phenotypic abnormalities might well be due to nulisomy of this region. In maternal and paternal UPD 14, an undetectable degree of mosaicism cannot be formally excluded. UPD 2 and 20 were connected with mosaictrisomy.

Established or probable phenotypes due to loss of imprinted genes due to UPD are listed in Table 2. Maternal UPD 15 is a well-established cause of the PWS, accounting for about $30 \%$ of the cases; paternal UPD 15 is responsible for the AS in about $1-2 \%$ of cases. Maternal UPD 7 leads to intrauterine and postnatal growth retardation with or without the full pattern of the Silver-Russell syndrome (SRS) [25] Segmental (for segment $11 \mathrm{p} 15)$ or mosaic paternal UPD 15 is the cause of the Beckwith-Wiedemann syndrome (BWS) in about $10 \%$ of cases [26, 27]. Furthermore, there is a suspicion that both paternal and maternal UPD 14 lead to phenotypic abnormalities in the probands although, as mentioned above, hidden mosaicism in these cases is not fully excluded and has been demonstrated in at least one instance $[21,28]$; the phenotypes of the different UPD 14 cases, both maternal and paternal, do not yet allow definition of a recognizable syndrome. In maternal UPD 16, intrauterine growth retardation is frequent, and occasionally other congenital anomalies, including anal atresia, occur [29]. However, it is not clear whether intrauterine growth retardation is due to loss of an imprinted gene or to the trisomic placenta, since other instances of placental, but not fetal, trisomy 16 unconnected to UPD also showed intrauterine growth retardation. Occasional congenital anomalies might also be due to homozygosity of a recessive allele and not the result of parental genomic imprinting.

\section{Maternal versus paternal UPD}

Increased maternal age is by far the most prominent cause of nondisjunction, and the majority of these events are due to first meiotic failure. Therefore, "correction" of an initial trisomy leading to uniparental maternal disomy, would usually lead to partial or 


\section{A. Schinzel}

Table 1 - Reported instances of UPD in humans

\begin{tabular}{|c|c|c|}
\hline Chromosome segment & Hetero-/isodisomy & Clinical disorder \\
\hline 2 mat & i? & (developmental delay)' \\
\hline 4 mat & $i(?)$ & none \\
\hline 5 pat & $\mathrm{i}$ & none (spinal muscolar atrophy) \\
\hline 6 pat & $\mathrm{i}$ & none \\
\hline 7 mat & $\mathbf{h}, \mathrm{i}$ & Silver-Russell (-like) syndrome \\
\hline 7 pat & $\mathrm{i}$ & none (chloride diarrhea) \\
\hline $8 \mathrm{mat} \ldots$ & $\mathrm{h}$ & MCA/MR syndrome' \\
\hline 9 mat & $h, i$ & (cartilage-hair hypoplasia) \\
\hline 11pter-p15.4 pat & $\mathrm{i}$ & BWS \\
\hline 11 pat mosaicism & $\mathrm{i}$ & BWS \\
\hline 13 mat & $\mathrm{i}$ & none \\
\hline 13 pat & $\mathrm{i}$ & none \\
\hline 14 pat & $\mathrm{h}, \mathrm{i}$ & MCA/MR syndrome \\
\hline 14 mat & $h, i$ & MCA syndrome \\
\hline $15 \mathrm{q} 11-\mathrm{q} 13 \mathrm{mat}$ & $h, i$ & AS \\
\hline $15 q 11.2-q 12$ pat & $h, i$ & PWS \\
\hline 16 mat & $h, i$ & growth retardation? \\
\hline 20 pat & $\mathrm{i}$ & (MCA/MR syndrome) ${ }^{1}$ \\
\hline 21 mat & $\mathrm{i}$ & none \\
\hline 21 pat & $\mathrm{i}$ & none \\
\hline 22 mat & $\mathrm{i}$ & none \\
\hline $\mathrm{X}$ pat & i & growth retardation?' \\
\hline $\mathrm{X}$ and $\mathrm{Y}$ pat & $\mathrm{h}$ & none \\
\hline XXX mat & $\mathrm{i}$ & severe $47, \mathrm{XXX}$ \\
\hline XXXX mat & $h$ and $i$ & severe $48, \mathrm{XXXX}$ \\
\hline
\end{tabular}

BWS $=$ Beckwith-Wiedemann Syndrome.

' Mosaicism for trisomy (monosomy) makes clinical evaluation difficult.

complete heterodisomy. The mean maternal age of these cases is increased, and is similar to or even higher, than mean maternal ages in autosomal trisomies. Robinson et al. [30] showed that, in their PWS patients with maternal UPD 15, the mean maternal age was higher than in trisomies 18 and 21 observed in the same population.

So far, virtually all cases of paternal UPD for any chromosome concerned isodisomy for its entire length. This observation agrees well with findings from the molecular investigation of the origin and mechanism of formation of paternally derived trisomy 21 : 
Table 2 - Phenotypes due to UPD

\begin{tabular}{lll}
\hline Chromosome & Origin & \multicolumn{1}{c}{ Phenotype } \\
\hline 7 & mat & IUGR, Silver-Russell syndrome \\
11 p15 & pat & BWS \\
11 (mosaic) & pat & BWS \\
14 & pat & MCA/MR \\
14 & mat & MCA/MR \\
15 & mat & PWS \\
15 & pat & A S \\
16 & mat & IUGR; prenatal demise \\
\hline
\end{tabular}

IUGR = Intrauterine growth rertardation.

BWS - Beckwith-Wiedemann syndrome.

the latter also showed a high incidence of mitotic nondisjunction as revealed by complete homozygosity for the paternal alleles [31]. As a consequence of these differences in origin between maternal and paternal UPD, the risk for the occurrence of recessive diseases due to homozygosity of a paternally inherited recessive mutated gene is higher in paternal UPD. Surprising at first glance is the observation by Robinson et al. [30] of an increased mean paternal age in cases of paternal UPD 15. However, one potential explanation could be that loss of the maternal homologue could, similar to the cause of maternal trisomy, be due to nondisjunction in "older" mothers, in which case a very early postzygotic reduplication of the paternal allele must have occurred in order to prevent early intrauterine demise of the conceptus.

\section{UPD and gene mapping}

Reduction to homozygosity in UPD may lead to homozygosity of recessive alleles present, in a heterozygous state, in one of the parents. In the first examples, maternal isodisomy 7 was demonstrated by the RFLP analysis of markers flanking the cystic fibrosis locus on chromosome 7 , prior to sequencing the gene and direct mutation analysis $[32,33]$. Subsequently, other recessive genes have been mapped, or their mapping has been confirmed, by UPD cases Table 3 [34]. In such instances, only one child would be affected, since UPD, and particularly isodisomy, occurs sporadically and only one parent will normally carry the mutation. Although the occurrence of recessive phenotypes will occur more often in complete uniparental isodisomy, it might also occur when heterodisomy is present and thus in the children of "old" mothers. Robinson et al. [35] could show that in the large majority of maternal UPD 15 cases with PWS with heterodisomy for segments close to the centromere (e.g. the PWS critical region), there were one or more switches due to recombination from hetero- to isodisomy and vice versa. Therefore, genes localized close to the telomeres are more likely to become occasionally homozygous in instances of UPD. 
Table 3 - Genes mapped or mapping confirmed by UPD cases

\begin{tabular}{lc}
\hline & Chromosome \\
\hline Spinal muscolar atrophy & 5 \\
Cystic fibrosis & 7 \\
Congenital chloride diarrhea & 7 \\
Cartilage-hair hypoplasia & 9 \\
B-Thalassemia & 11 \\
Rod monochromacy & 14 \\
Bloom syndrome & 15 \\
$\alpha$-Thalassemia & 16 \\
\hline
\end{tabular}

\section{UPD as a source for the assessment of imprinted genes or chromosome regions}

As seen from Table 1, UPD may cause the PWS, SRS, AS and BWS. Characteristic for all of these four syndromes are the following: predominantly sporadic occurrence, but occurrence in several family members in a small minority of cases; alteration of growth and mental development (with the exception for the latter in the SRS); mild-to-distinct patterns of minor dysmorphic signs, and the rare occurrence of major organ malformations. Thus, candidates for the search for further imprinted genes or chromosome regions might be instances with similar characteristics. It should also be considered that other examples of UPD could share the origins of PWS and AS: loss of the active allele of an imprinted gene through mutation or deletion in the majority, and through UPD in a minority of the cases. For the SRS, which is undoubtedly also heterogenous in origin, it is possible that a majority of cases are due to deletion or mutation of the active paternal homologue of an imprinted gene on chromosome 7, which has not yet been discovered.

\section{UPD and confined placental mosaicism}

It is important to be aware of the risk for UPD in instances in which trisomy or mosaic trisomy determined at chorionic villus examination was not confirmed upon examination of cultured amniocytes or fetal lymphocytes. These cases are predominantly confined to pregnancies of "old" mothers, and the risk is therefore almost entirely confined to maternal disomy. Therefore, before giving the information to the couple that the fetus, because its karyotype is normal diploid, is most likely going to be normal, maternal disomy has to be excluded when there is placental (mosaic) trisomy 7,14 or 15. Maternal UPD 15 would invariably be connected to the PWS phenotype, maternal UPD 7 to intrauterine growth retardation and maternal disomy 14 most likely to the MCA/MR syndrome. In cases of maternal UPD for other chromosomes, it is still very difficult to predict the outcome. Placental dysfunction might be the cause of maternal UPD 11 and 16. In addition, as outlined above, there is still a risk for "hidden" undetected trisomy mosaicism in the fetus, as well as for the occurrence of recessive phenotypes, due to reduction to homozygosity for mutated maternal recessive alleles, especially of genes mapping close to telomeres. 


\section{Errors in interpreting UPD}

The abnormal phenotype found in a child with UPD might be due to undetected mosaic trisomy or reduction to homozygosity of a rare mutated recessive gene, rather than to loss of the active homologue of an imprinted gene or genes.

Intrauterine growth retardation might not be due to UPD, but may rather be caused by dysfunction of the trisomic placenta.

\section{REFERENCES}

1. Engel E: A new genetic concept: Uniparental disomy and its potential effect, isodisomy. Am J Med Genet 1980; 6: 137-143.

2. Carpenter NJ, Say B, Barber ND: A homozygote for pericentric inversion of chromosome 4. J Med Genet 1982; 19: 469-471.

3. Palmer CG, Schwartz S, Hodes ME: Transmission of a balanced homologous $t(22 q ; 22 q)$ translocation from mother to normal daughter. Clin Genet 1980, 17: 418-422.

4. Kirkels VGHJ, Hustinx TWJ, Scheres JMJC: Habitual abortion and translocation (22q;22q): Unexpected transmission from a mother to her phenotypically normal daughter. Clin Genet $1980 ; 18: 456-461$.

5. Cattanach BM, Jones J: Genetic imprinting in the mouse: Implications for gene regulation. $J$ Inherit Metab Dis 1994; 17: 404-420.

6. Robinson WP, Bernasconi F, Basaran S, Yüksel-Apak M, Neri G, Serville F, Balicek P, Haluza R, Farah LMS, Luleci G, Schinzel AA: A somatic origin of homologous Robertsonian translocations and isochromosomes. Am J Hum Genet 1994; 54: 290-302.

7. Lindenbaum RH, Woods CG, Norbury CG, Povey S, Rysiecki G: An individual with maternal disomy of chromosome 4 and iso(4p). Am J Hum Genet 1991; 49: A285.

8. Eggerding FA, Schonberg SA, Chehab FF, Norton ME, Cox VA, Epstein CJ: Uniparental isodisomy for paternal $7 p$ and maternal $7 q$ in a child with growth retardation. Am J Hum Genet 1994; 55: 253-265.

9. Nicholls RD, Knoll JHM, Butler MG, Karam S, LaLande M: Genetic imprinting suggested by maternal heterodisomy in non-deletion Prader-Willi syndrome. Nature 342: 281-285.

10. Smith A, Murray R, Dendulk G: Familial deletion. Ann Genet 1983; 26: 91-93.

11. Smith A, Dengler DR, Berankova J, Woods CG, Triolo O: Familial unbalanced translocation $\mathfrak{t}(8 ; 15)(\mathrm{p} 23.3 ; \mathrm{q} 11)$ with uniparental disomy in Angelman syndrome. Hum Genet 1994; 93: 471473.

12. Smith A, Noel M: A girl with the Prader-Willi syndrome and Robertsonian translocation 45, $\mathrm{XX}, \mathrm{t}(14 ; 15)(\mathrm{p} 11 ; \mathrm{q} 11)$ which was present in three normal family members. Hum Genet 1980 ; 55: 271-273.

13. Wu RH, Hasen J, Warburton D: Primary hypogonadism and 13/15 chromosome translocation in Prader-Labhart-Willi syndrome. Hormone Res 1981; 15: 148-158.

14. Smeets DFCM, Hamel BCJ, Nelen MR, Smeets HJM, Bollen JHM, Smits APT, van Oost BA: Prader-Willi syndrome and Angelman syndrome in cousins from a family with a translocation between chromosomes 6 and 15. New Engl J Med 1992; 326: 807-811.

15. Temple JK, Cockwell A, Hassold T, Pettay D, Jacobs P: Maternal uniparental disomy for chromosome 14. J Med Genet 1991; 28: 511-514.

16. Pentao L, Lewis RA, Ledbetter DH, Patel PI, Lupski JR: Maternal uniparental isodisomy of chromosome 14: Association with autosomal recessive rod monochromacy. Am J Hum Genet 1992; 50: 690-699.

17. Woodage T, Prasad M, Dixon JW, Selby RE, Romain DR, Columbano-Green LM, Graham D, Rogan PK, Seip JR, Smith A, Trent RJ: Bloom syndrome and maternal uniparental disomy for chromosome 15. Am J Hum Genet 1994; 55: 74-80. 
18. Sulisalo T, de la Chapelle A, Kaitila I: Uniparental disomy as an explanation of presumptive low penetrance. Am J Hum Genet 1994; 55: A7.

19. Welch TR, Beischel L, Choi E, Balakrishnan K, Bishof NA: Uniparental isodisomy 6 associated with deficiency of the fourth component of complement. J Clin Invest 1990; 86: 675-678.

20. Morichon-Delvallez N, Seques B, Pinson MP, Berube D, Dommerques M, Aubry MC, Cessot F, Lyonnet S, Nunnich A, Vekemans M: Maternal uniparental disomy for chromosome 14 by secondary nondisjunction of an initial trisomy. Am J Hum Genet 1994; 55: A379.

21. Sirchia SM, de Andreis C, Pariani S, Grimoldi MG, Molinari A, Buscaglia M, Simoni G: Chromosome 14 maternal uniparental disomy in the euploid cell line of a fetus with mosaic 46 , XX/47, XX, +14 karyotype. Hum Genet 1994; 94: 355-358.

22. Purvis-Smith SG, Saville T, Manass S, Yip MY, Lam-Po-Tang PRL, Duffy B, Johnston H, et al Uniparental disomy 15 resulting from fcorrection of an initial trisomy 15 . Am J Hum Genet 1992; 50: 1348-1350,

23. Cassidy SB, Lai LW, Erickson RP, Magnuson L, Thomas E, Gendron, Hermann J: Trisomy 15 with loss of the paternal 15 as a cause of Prader-Willi syndrome due to maternal disomy. Am J Hum Genet 1992; 51: 701-708.

24. Kalousek DK, Langlois S, Barrett IJ, Yam I, Wilson DR, Howard-Peebles PN, Johnson MP, et al.: Uniparental disomy for chromosome 16 in humans. Am J Hum Genet 1993; 52: 8-16.

25. Kotzot D, Schmitt S, Bernasconi F, Robinson WP, Lurie IW, Ilyina H, Méhes K, Hamel BCJ, Otten BJ, Hergersberg M, Werder E, Schoenle E, Schinzel A: Uniparental disomy 7 in SilverRussell syndrome and primordial growth retardation. Hum Mol Genet in press.

26. Henry I, Bonaiti-Pellie C, Chehensse V, Beldjord C, Schwartz C, Utermann G, Junien C: Uniparental paternal disomy in a genetic cancer-predisposing syndrome. Nature 1991; 351: 665667.

27. Henry I, Puech A, Riesewijk A, Ahnine L, Mannens M, Beldjord C, Bitoun P, Tournade MF, Landrieu P, Junien C: Somatic mosaicism for partial paternal isodisomy in Wiedemann-Beckwith syndrome: A post-fertilization event. Eur J Hum Genet 1993; 1: 19-29.

28. Antonarakis SE, Blouin JL, Maher J, Avramopoulos D, Thomas G, Talbot CC Jr. Maternal uniparental disomy for human chromosome 14, due to loss of a chromosome 14 from somatic cells with $\mathrm{t}(13 ; 14)$ trisomy 14 . Am J Hum Genet 1993; 52: 1145-1152.

29. Wolstenholme J: An audit of trisomy 16 in man. Prenat Diagn 1995; 15:109-121.

30. Robinson WP, Bernasconi F, Mutirangura A, Ledbetter DH, Langlois S, Malcolm S, Morris M, et al: Nondisjunction of chromosome 15: Origin and recombination. Am J Hum Genet 1993; 53: 740-751.

31. Antonarakis SE, Avramopoulos D, Blouin JL, Talbot CC, Schinzel AA: Mitotic (somatic cell) errors cause trisomy 21 in about $4.5 \%$ of cases and are not associated with advanced maternal age. Nat Genet 1993; 3: 146-150.

32. Spence JE, Perciaccante RG, Greig GM: Uniparental disomy as a mechanism for human genetic disease. Am J Hum Genet 1988; 42: 217-226.

33. Voss R, Ben-Simon E, Avital A, et al: Isodisomy of chromosome 7 in a patient with cystic fibrosis: could uniparental disomy be common in humans? Am J Hum Genet 1989; 42: 373380 .

34. Schinzel A, McKusick V, Francomano C: Report of the committee for clinical disorders and chromosome aberrations. Human Gene Mapping 1994; A Compendium. Cuticchia AJ Pearson PL (eds): Baltimore, The Johns Hopkins University Press, 1995.

35. Robinson WP, Bottani A, Yagang X, Balakrishnan J, Binkert F, Mächler M, Prader A, Schinzel AA: Molecular, cytogenetic, and clinical investigations of Prader-Willi syndrome patients. Am J Hum Genet 1991; 49: 1219-1234.

Correspondence: Albert Schinzel, Institute of Medical Genetics, University of Zürich, Rämistrasse 74, CH-8001 Zürich, Switzerland. 